\title{
Concentrations of lead in the tissues of children
}

\author{
P S I BARRY \\ From the Associated Octel Company Limited, Ellesmere Port, South Wirral L65 4HF, UK
}

ABSTRACT Twenty-four different tissues from 73 children and infants, including stillbirths, were analysed for lead content. In the youngest group of 49 infants aged under 1 year, including 14 stillbirths, the mean concentrations of lead in their soft tissues were all less than $0.3 \mathrm{ppm}$ and nearly all less than the concentrations found in the soft tissues of older children, or of adults. The mean concentrations of lead in the bones in the infant group were greater than in their soft tissues, but still less than $1 \mathrm{ppm}$, and were 10-40 times less than in adult bones and about three times less than in the bones of older children. Lower concentrations of lead were observed in the tissues of stillbirths than in those of neonatal live births, at a $95 \%$ level of significance by analysis of variance. In 24 children aged 1-16 there was no clear evidence of increase of lead concentrations in the bones with increasing age; neither was there evidence of a difference in the concentrations of lead in types of bone. Although the mean concentrations in the bones were greater in the children aged 1-16 than in those of infants aged under 1 year, the data did not suggest that a progressive accumulation of lead occurred in the bones, probably before the end of the second decade of life, by which time the growing phase will be nearing completion. In 18 children aged 1-9 and in six children aged 11-16 the concentrations of lead in the soft tissues were similar, and comparable with those observed in women.

The ratio differences between ash-weight and wet-weight measurement in the different types of bone in children did not differ proportionately from the adult ratios, suggesting a similarity in the patterns of deposition of lead in bone, irrespective of age. No differences in tissue lead concentrations by sex were observed in the infant group of children, or when the concentrations in the tissues were related to the years in which the samples were obtained. Individual tissues showed different concentrations and patterns of distribution of lead, which were skewed more towards low values in the infant group than in older children. The results of other studies, of which there have not been many, were found to be in general agreement with those reported here. The exposure of infants to lead appeared to be less than in older children or in adults, probably for reasons associated with lack of availability and parental care.

Considerable interest, with an associated concern, has been expressed in recent years in the potential effects of the lead in our environment on the health of young children. It has been suggested that children may be more sensitive to lead than adults and, for reasons of metabolic difference, may also absorb proportionately more lead by the gastrointestinal and pulmonary routes.

To assess the concentrations of lead present in contemporary children of different ages, postmortem tissue samples were obtained for analysis of their lead content and the results compared with

Received 31 January 1980

Accepted 6 March 1980 contemporary adult values. Samples were obtained, most of them since 1975, between 1966 and 1979 from children drawn from a predominantly industrialised area in the north-west of England.

Twenty-four different types of tissue were obtained from 73 children aged from stillbirth to 16 years. The children were divided into age groups comprising stillbirths and those with a very short postpartum life span (29 cases), from 1 to 11 months (20), from 1-9 years (18), and from 11-16 (6). The lead content in the tissues in these age groups was compared with the lead content in the same tissues in 60 men and 36 women (aged 18-94) with no history of occupational exposure to lead.

For various reasons it was not always possible to 
obtain tissue samples that had been requested, so that, for the most part, the number of samples analysed shown in the results did not equate with the number of individual children from whom samples were obtained. None of the children had been known to have had an unusual exposure to lead, but in a few cases the results suggested an excess exposure, relative to their peers; these will be referred to individually, as also will morbidity and the causes of death in the separate age groups.

\section{Analytical procedures}

Up to May 1977 the technique used for analysing lead in the tissues was the dithizone method of Bambach and Burkey, described by Barry and
Mossman. ${ }^{2}$ Many of the samples received after May 1977 were too small in size to be suitable for analysis by the dithizone method. From then, up to August 1978 , the tissues of 13 children were analysed by atomic absorption spectrophotometry (AAS) after digestion of the samples with nitric acid.

From September 1978 to June 1979, after which no further samples were obtained, the tissues of 10 infants, all of which were of even smaller sample size, were analysed by AAS after dissolution of the samples in a quaternary ammonium hydroxide solution in toluene, known as Soluene 350. Both of the AAS methods were checked against the Bambach and Burkey dithizone method before use.

Samples that were received, but not analysed immediately on receipt at the laboratory, were

Table 1 Concentrations of lead in tissues of infant children (ppm wet weight)

\begin{tabular}{|c|c|c|c|c|c|c|c|c|c|c|c|c|}
\hline \multirow[t]{2}{*}{ Tissue } & \multicolumn{4}{|c|}{$0-12$ days } & \multicolumn{4}{|c|}{$1-11$ months } & \multicolumn{4}{|c|}{$0-11$ months } \\
\hline & No & Mean & $S D$ & Range & No & Mean & $S D$ & Range & No & Mean & $S D$ & Range \\
\hline \multicolumn{13}{|l|}{ Blood } \\
\hline $\begin{array}{l}(\mu \mathrm{mol} / \mathrm{l}) \\
(\mu \mathrm{g} / 100 \mathrm{ml})\end{array}$ & 28 & $\begin{array}{l}0.56 \\
11.5\end{array}$ & $\begin{array}{l}0 \cdot 28 \\
5 \cdot 8\end{array}$ & $\begin{array}{l}0 \cdot 19-1 \cdot 21 \\
4 \cdot 0-25 \cdot 0\end{array}$ & 15 & $\begin{array}{l}0.56 \\
11.5\end{array}$ & $\begin{array}{l}0 \cdot 38 \\
7 \cdot 9\end{array}$ & $\begin{array}{l}0 \cdot 05-1 \cdot 35 \\
1 \cdot 1-28 \cdot 0\end{array}$ & 43 & $\begin{array}{l}0.56 \\
11 \cdot 5\end{array}$ & $\begin{array}{l}0 \cdot 31 \\
6 \cdot 5\end{array}$ & $\begin{array}{l}0 \cdot 05-1 \cdot 35 \\
1 \cdot 1-28 \cdot 0\end{array}$ \\
\hline \multicolumn{13}{|l|}{ Bone: } \\
\hline Rib & $\begin{array}{l}29 \\
28\end{array}$ & $\begin{array}{l}0.95 \\
0.79\end{array}$ & $\begin{array}{l}1.06 \\
0.63\end{array}$ & $\begin{array}{l}0.03-5 \cdot 40 \\
0.03-2 \cdot 30\end{array}$ & 20 & 0.90 & 0.98 & $0.01-2.90$ & $\begin{array}{l}49 \\
48\end{array}$ & $\begin{array}{l}0.93 \\
0.84\end{array}$ & $\begin{array}{l}1.02 \\
0.78\end{array}$ & $\begin{array}{l}0.01-5.40 \\
0.01-2.90\end{array}$ \\
\hline Tibia & 29 & 0.56 & 0.43 & $0.02-1.90$ & $\begin{array}{l}16 \\
15\end{array}$ & $\begin{array}{l}0.82 \\
0.61\end{array}$ & $\begin{array}{l}0.93 \\
0.40\end{array}$ & $\begin{array}{l}0 \cdot 04-4 \cdot 00 \\
0 \cdot 04-1 \cdot 34\end{array}$ & $\begin{array}{l}45 \\
44\end{array}$ & $\begin{array}{l}0.65 \\
0.58\end{array}$ & $\begin{array}{l}0.64 \\
0.42\end{array}$ & $\begin{array}{l}0.02-4 \cdot 00 \\
0.02-1 \cdot 90\end{array}$ \\
\hline Calvaria & 25 & 0.69 & 0.54 & $0 \cdot 10-2 \cdot 10$ & 14 & 0.61 & 0.42 & $0 \cdot 06-0 \cdot 84$ & 39 & 0.66 & 0.49 & $0 \cdot 06-2 \cdot 10$ \\
\hline Liver & 29 & $0 \cdot 13$ & 0.07 & $0.03-0.37$ & $\begin{array}{l}20 \\
18\end{array}$ & $\begin{array}{l}0.41 \\
0.26\end{array}$ & $\begin{array}{l}0.50 \\
0.19\end{array}$ & $\begin{array}{l}0 \cdot 06-2 \cdot 10 \\
0 \cdot 06-0 \cdot 84\end{array}$ & $\begin{array}{l}49 \\
47\end{array}$ & $\begin{array}{l}0 \cdot 25 \\
0 \cdot 18\end{array}$ & $\begin{array}{l}0 \cdot 35 \\
0 \cdot 12\end{array}$ & $\begin{array}{l}0 \cdot 03-2 \cdot 10 \\
0 \cdot 03-0 \cdot 84\end{array}$ \\
\hline $\begin{array}{l}\text { Spleen } \\
\text { Kidney: }\end{array}$ & 28 & $0 \cdot 15$ & $0 \cdot 14$ & $0 \cdot 02-0.54$ & 20 & $0 \cdot 15$ & $0 \cdot 13$ & $0 \cdot 02-0 \cdot 54$ & 48 & $0 \cdot 15$ & 0.14 & $0 \cdot 02-0.54$ \\
\hline Cortex & 21 & $0 \cdot 12$ & 0.06 & $0.02-0.25$ & $\begin{array}{l}16 \\
15\end{array}$ & $\begin{array}{l}0.31 \\
0.17\end{array}$ & $\begin{array}{l}0.55 \\
0.14\end{array}$ & $\begin{array}{l}0.01-2.30 \\
0.01-0.47\end{array}$ & $\begin{array}{l}37 \\
36\end{array}$ & $\begin{array}{l}0 \cdot 20 \\
0 \cdot 14\end{array}$ & $\begin{array}{l}0.26 \\
0.09\end{array}$ & $\begin{array}{l}0 \cdot 02-2 \cdot 30 \\
0 \cdot 02-0 \cdot 47\end{array}$ \\
\hline Medulla & 21 & 0.11 & 0.09 & $0.01-0.31$ & $\begin{array}{l}16 \\
15\end{array}$ & $\begin{array}{l}0 \cdot 16 \\
0 \cdot 14\end{array}$ & $\begin{array}{l}0.13 \\
0.08\end{array}$ & $\begin{array}{l}0 \cdot 01-0 \cdot 54 \\
0 \cdot 01-0 \cdot 26\end{array}$ & $\begin{array}{l}37 \\
36\end{array}$ & $\begin{array}{l}0 \cdot 13 \\
0 \cdot 12\end{array}$ & $\begin{array}{l}0 \cdot 10 \\
0.08\end{array}$ & $\begin{array}{l}0 \cdot 01-0.54 \\
0.01-0.31\end{array}$ \\
\hline Combined & 29 & $0 \cdot 10$ & 0.07 & $0 \cdot 02-0.27$ & $\begin{array}{l}20 \\
19\end{array}$ & $\begin{array}{l}0.21 \\
0 \cdot 15\end{array}$ & $\begin{array}{l}0.30 \\
0 \cdot 10\end{array}$ & $\begin{array}{l}0.01-1 \cdot 42 \\
0.01-0.37\end{array}$ & $\begin{array}{l}49 \\
48\end{array}$ & $\begin{array}{l}0.15 \\
0 \cdot 12\end{array}$ & $\begin{array}{l}0.16 \\
0.08\end{array}$ & $\begin{array}{l}0 \cdot 01-1 \cdot 42 \\
0 \cdot 01-0 \cdot 37\end{array}$ \\
\hline Adrenal & 25 & $0 \cdot 20$ & $0 \cdot 20$ & $0.02-0.82$ & $\begin{array}{l}14 \\
13\end{array}$ & $\begin{array}{l}0 \cdot 30 \\
0 \cdot 20\end{array}$ & $\begin{array}{l}0.41 \\
0 \cdot 18\end{array}$ & $\begin{array}{l}0.01-1.60 \\
0.01-0.72\end{array}$ & $\begin{array}{l}39 \\
38\end{array}$ & $\begin{array}{l}0 \cdot 24 \\
0 \cdot 20\end{array}$ & $\begin{array}{l}0 \cdot 27 \\
0 \cdot 19\end{array}$ & $\begin{array}{l}0.01-1 \cdot 60 \\
0.01-0.82\end{array}$ \\
\hline Pancreas & 17 & $0 \cdot 19$ & $0 \cdot 14$ & $0.02-0.53$ & $\begin{array}{l}15 \\
14\end{array}$ & $\begin{array}{l}0.39 \\
0.24\end{array}$ & $\begin{array}{l}0.61 \\
0 \cdot 17\end{array}$ & $\begin{array}{l}0.01-2.50 \\
0.01-0.56\end{array}$ & $\begin{array}{l}32 \\
31\end{array}$ & $\begin{array}{l}0 \cdot 28 \\
0 \cdot 21\end{array}$ & $\begin{array}{l}0 \cdot 36 \\
0 \cdot 16\end{array}$ & $\begin{array}{l}0.01-2 \cdot 50 \\
0.01-0.56\end{array}$ \\
\hline Thymus & $\begin{array}{l}19 \\
18\end{array}$ & $\begin{array}{l}0.13 \\
0.09\end{array}$ & $\begin{array}{l}0.17 \\
0.07\end{array}$ & $\begin{array}{l}0 \cdot 02-0 \cdot 78 \\
0 \cdot 02-0 \cdot 28\end{array}$ & 11 & 0.11 & $0 \cdot 11$ & $0.01-0.36$ & $\begin{array}{l}30 \\
29\end{array}$ & $\begin{array}{l}0 \cdot 12 \\
0 \cdot 10\end{array}$ & $\begin{array}{l}0.15 \\
0.09\end{array}$ & $\begin{array}{l}0.01-0.78 \\
0.01-0 \cdot 36\end{array}$ \\
\hline Thyroid & $\begin{array}{l}16 \\
14\end{array}$ & $\begin{array}{l}0 \cdot 26 \\
0 \cdot 11\end{array}$ & $\begin{array}{l}0.41 \\
0.07\end{array}$ & $\begin{array}{l}0 \cdot 02-1 \cdot 30 \\
0 \cdot 02-0 \cdot 26\end{array}$ & $\begin{array}{l}13 \\
12\end{array}$ & $\begin{array}{l}0 \cdot 21 \\
0 \cdot 14\end{array}$ & $\begin{array}{l}0.28 \\
0.09\end{array}$ & $\begin{array}{l}0 \cdot 01-1 \cdot 10 \\
0 \cdot 01-0 \cdot 27\end{array}$ & $\begin{array}{l}29 \\
26\end{array}$ & $\begin{array}{l}0 \cdot 24 \\
0 \cdot 12\end{array}$ & $\begin{array}{l}0.36 \\
0.08\end{array}$ & $\begin{array}{l}0.01-1 \cdot 30 \\
0 \cdot 01-0 \cdot 27\end{array}$ \\
\hline Brain cortex & 27 & 0.05 & 0.06 & $0.01-0.20$ & 19 & 0.07 & 0.08 & $0 \cdot 01-0.34$ & 46 & 0.06 & 0.07 & $0.01-0.34$ \\
\hline Lung & 29 & 0.06 & 0.04 & $0 \cdot 01-0.16$ & 20 & 0.07 & 0.04 & $0 \cdot 02-0 \cdot 18$ & 49 & 0.06 & 0.04 & $0 \cdot 01-0.18$ \\
\hline Heart & $\begin{array}{l}29 \\
27\end{array}$ & $\begin{array}{l}0.10 \\
0.05\end{array}$ & $\begin{array}{l}0.24 \\
0.03\end{array}$ & $\begin{array}{l}0 \cdot 01-1 \cdot 30 \\
0 \cdot 01-0 \cdot 15\end{array}$ & 19 & 0.05 & 0.04 & $0.01-0.19$ & $\begin{array}{l}48 \\
46\end{array}$ & $\begin{array}{l}0.08 \\
0.05\end{array}$ & $\begin{array}{l}0.16 \\
0.03\end{array}$ & $\begin{array}{l}0 \cdot 01-1 \cdot 30 \\
0 \cdot 01-0 \cdot 19\end{array}$ \\
\hline Aorta & 20 & $\begin{array}{l}0 \cdot 22 \\
0 \cdot 13\end{array}$ & $\begin{array}{l}0 \cdot 29 \\
0 \cdot 11\end{array}$ & $\begin{array}{l}0.02-1 \cdot 10 \\
0.02-0.40\end{array}$ & 14 & $0 \cdot 19$ & $0 \cdot 15$ & $0.05-0.48$ & $\begin{array}{l}34 \\
32\end{array}$ & $\begin{array}{l}0.21 \\
0.15\end{array}$ & $\begin{array}{l}0 \cdot 23 \\
0 \cdot 13\end{array}$ & $\begin{array}{l}0.02-1 \cdot 10 \\
0.02 \cdot 0 \cdot 48\end{array}$ \\
\hline Fat & $\begin{array}{l}28 \\
15\end{array}$ & $\begin{array}{l}0.09 \\
0.18\end{array}$ & $\begin{array}{l}0.09 \\
0.16\end{array}$ & $\begin{array}{l}0 \cdot 01-0 \cdot 31 \\
0 \cdot 02-0 \cdot 55\end{array}$ & $\begin{array}{l}16 \\
10\end{array}$ & $\begin{array}{l}0.06 \\
0.14\end{array}$ & $\begin{array}{l}0.05 \\
0.09\end{array}$ & $\begin{array}{l}0.02-0 \cdot 29 \\
0 \cdot 01-0 \cdot 30\end{array}$ & $\begin{array}{l}44 \\
25\end{array}$ & $\begin{array}{l}0.08 \\
0.16\end{array}$ & $\begin{array}{l}0 \cdot 08 \\
0 \cdot 13\end{array}$ & $\begin{array}{l}0 \cdot 01-0 \cdot 31 \\
0 \cdot 01-0.55\end{array}$ \\
\hline Skin & $\begin{array}{l}27 \\
25\end{array}$ & $\begin{array}{l}0 \cdot 35 \\
0 \cdot 24\end{array}$ & $\begin{array}{l}0.46 \\
0.20\end{array}$ & $\begin{array}{l}0.02-1.90 \\
0.02-0.65\end{array}$ & 14 & $0 \cdot 18$ & $0 \cdot 18$ & $0.01-0.63$ & 41 & 0.29 & 0.36 & $0.01-1.90$ \\
\hline Dense connective tissue & 23 & $\begin{array}{l}0 \cdot 24 \\
0 \cdot 14\end{array}$ & $\begin{array}{l}0 \cdot 20 \\
0 \cdot 14\end{array}$ & $\begin{array}{l}0.02-0.65 \\
0.01-0.48\end{array}$ & 13 & $0 \cdot 12$ & 0.08 & $0.03-0.35$ & $\begin{array}{l}39 \\
36\end{array}$ & $\begin{array}{l}0.22 \\
0.13\end{array}$ & $\begin{array}{l}0.19 \\
0 \cdot 11\end{array}$ & $\begin{array}{l}0.01-0.65 \\
0.01-0.48\end{array}$ \\
\hline Cartilage & 25 & $0 \cdot 16$ & $0 \cdot 15$ & $0.01-0.46$ & $\begin{array}{l}14 \\
13\end{array}$ & $\begin{array}{l}0.27 \\
0 \cdot 13\end{array}$ & $\begin{array}{l}0.54 \\
0.13\end{array}$ & $\begin{array}{l}0 \cdot 02-2 \cdot 10 \\
0 \cdot 02-0 \cdot 50\end{array}$ & $\begin{array}{l}39 \\
38\end{array}$ & $\begin{array}{l}0.19 \\
0.14\end{array}$ & $\begin{array}{l}0 \cdot 28 \\
0 \cdot 14\end{array}$ & $\begin{array}{l}0.01-2 \cdot 10 \\
0 \cdot 01-0 \cdot 50\end{array}$ \\
\hline Gastrointestinal tract: & & & & & & & & & & & & \\
\hline Stomach & 29 & $0 \cdot 13$ & $0 \cdot 11$ & $0.02-0.47$ & 18 & 0.06 & 0.04 & $0 \cdot 01-0 \cdot 14$ & 47 & $0 \cdot 11$ & 0.09 & $0.01-0.47$ \\
\hline Caecum & 23 & 0.25 & $0 \cdot 27$ & $0 \cdot 01-1 \cdot 10$ & 16 & 0.09 & 0.08 & $0.01-0.37$ & 39 & $0 \cdot 19$ & $0 \cdot 19$ & $0 \cdot 01-1 \cdot 10$ \\
\hline & 21 & $0 \cdot 19$ & $0 \cdot 16$ & $0.01-0.58$ & & & & & 37 & $0 \cdot 15$ & $0 \cdot 13$ & $0.01-0.58$ \\
\hline Midgut & 29 & $0 \cdot 14$ & $0 \cdot 10$ & $0 \cdot 02-0 \cdot 37$ & 17 & 0.09 & 0.05 & $0 \cdot 02-0 \cdot 22$ & 46 & $0 \cdot 12$ & 0.08 & $0 \cdot 02-0.37$ \\
\hline
\end{tabular}

Figures in italics exclude highest values, 
weighed and then kept in deep freeze conditions before analysis at a later date.

\section{Discussion of results}

The mean concentrations of lead found in the tissues of the children and in adults are shown in tables $1-4$, expressed in parts per million on wet-weight measurement. The figures in italics represent the values found when a high outlying result was excluded from the total.

The neonatal group of children, of both sexes, whose results are shown in table 1 , was composed of 14 stillbirths, 14 who died within three days of birth, and one who died on the twelfth day after birth. In most cases birth weights were less than the average for normal healthy full-term infants. Causes of death were attributed to prematurity, intrauterine asphyxia, atelectasis, pre-eclamptic toxaemia, and congenital defects, such as patent foramen ovale, hydramnios, spina bifida, hydronephrosis, diaphragmatic hernia, and transposition of the great vessels.
The 12-day-old boy died from a persistent truncus arteriosus. One girl, who was born two months prematurely and died four hours after birth, showed rather higher concentrations of lead in some of her tissues than did the other infants in the group. No history of undue maternal exposure to lead was obtained, but this infant had probably been exposed to lead in-utero to a greater degree than her peers.

Table 1 also shows the results in the group of 20 infants, of both sexes, aged from 1 to 11 months. Causes of death included asphyxia, sudden deaths of unknown aetiology, chest infections, meningitis, and congenital defects. In one 8-month-old girl, who had sucked painted toys, lead encephalopathy was suspected clinically, but this was not confirmed by the results of blood and tissue analyses. In another girl aged 9 months the concentrations of lead in the tissues were higher than in those of others in the group, although not appreciably so. There was no obvious explanation for the difference, but she had suffered from chronic otitis media and had died from meningitis; with such a history it is not inconceivable

Table 2 Concentrations of lead in tissues of stillbirths and neonatal live births aged less than 2 weeks (ppm wet weight)

\begin{tabular}{|c|c|c|c|c|c|c|c|c|}
\hline \multirow[t]{2}{*}{ Tissue } & \multicolumn{4}{|c|}{ Stillbirths } & \multicolumn{4}{|c|}{ Live births } \\
\hline & No & Mean & $S D$ & Range & No & Mean & $S D$ & Range \\
\hline \multicolumn{9}{|l|}{ Blood } \\
\hline $\begin{array}{l}(\mu \mathrm{mol} / \mathrm{l}) \\
(\mu \mathrm{g} / 100 \mathrm{ml})\end{array}$ & 13 & $\begin{array}{c}0.51 \\
10 \cdot 6\end{array}$ & $\begin{array}{l}0 \cdot 25 \\
5 \cdot 2\end{array}$ & $\begin{array}{l}0 \cdot 20-1 \cdot 21 \\
4 \cdot 2-25 \cdot 0\end{array}$ & 15 & $\begin{array}{c}0 \cdot 59 \\
12 \cdot 3\end{array}$ & $\begin{array}{l}0 \cdot 31 \\
6 \cdot 4\end{array}$ & $\begin{array}{l}0 \cdot 19-1 \cdot 21 \\
4 \cdot 0-25 \cdot 0\end{array}$ \\
\hline \multicolumn{9}{|l|}{ Bone: } \\
\hline Rib & 14 & 0.62 & $0 \cdot 58$ & $0 \cdot 09-1 \cdot 51$ & $\begin{array}{l}15 \\
14\end{array}$ & $\begin{array}{l}1.25 \\
0.97\end{array}$ & $\begin{array}{l}1.30 \\
0.66\end{array}$ & $\begin{array}{l}0 \cdot 08-5 \cdot 40 \\
0 \cdot 08-2 \cdot 30\end{array}$ \\
\hline Tibia & 14 & 0.49 & 0.40 & $0 \cdot 02-1 \cdot 53$ & 15 & 0.63 & $0 \cdot 46$ & $0.06-1.90$ \\
\hline Calvaria & 11 & 0.46 & $0 \cdot 29$ & $0 \cdot 14-0.96$ & 14 & 0.87 & 0.62 & $0 \cdot 10-2 \cdot 10$ \\
\hline Liver & 14 & $0 \cdot 10$ & 0.04 & $0 \cdot 03-0 \cdot 17$ & 15 & $0 \cdot 16$ & 0.08 & $0.05-0.37$ \\
\hline Spleen & 13 & 0.12 & $0 \cdot: 4$ & $0.02-0.53$ & 15 & $0 \cdot 17$ & $0 \cdot 14$ & $0 \cdot 04-0.54$ \\
\hline \multicolumn{9}{|l|}{ Kidney: } \\
\hline Cortex & 9 & 0.09 & 0.06 & $0 \cdot 04-0 \cdot 25$ & 12 & $0 \cdot 14$ & 0.06 & $0.02-0.22$ \\
\hline Medulla & 9 & 0.09 & $0 \cdot 10$ & $0.01-0.27$ & 12 & 0.13 & 0.08 & $0.01-0.31$ \\
\hline Combined & 14 & 0.08 & 0.06 & $0.02-0.26$ & 15 & $0 \cdot 13$ & 0.07 & $0.02-0.27$ \\
\hline Adrenal & 11 & $0 \cdot 15$ & $0 \cdot 15$ & $0.02-0.46$ & 14 & $0 \cdot 23$ & $0 \cdot 23$ & $0.03-0.82$ \\
\hline Pancreas & 9 & $0 \cdot 16$ & 0.17 & $0.02-0.53$ & 8 & 0.22 & $0 \cdot 10$ & $0.09-0.35$ \\
\hline \multirow[t]{2}{*}{ Thymus } & 11 & $0 \cdot 17$ & 0.22 & $0.02-0.78$ & 8 & 0.07 & 0.03 & $0.03-0.12$ \\
\hline & 10 & $0 \cdot 11$ & 0.08 & $0.02-0 \cdot 28$ & & & & \\
\hline \multirow[t]{2}{*}{ Thyroid } & 8 & $0 \cdot 11$ & 0.09 & $0 \cdot 02-0 \cdot 26$ & 8 & 0.41 & 0.55 & $0 \cdot 05-1 \cdot 30$ \\
\hline & & & & & 6 & 0.11 & 0.06 & $0 \cdot 05-0 \cdot 18$ \\
\hline Brain cortex & 12 & 0.03 & 0.03 & $0.01-0.09$ & 15 & 0.07 & 0.07 & $0.01-0.20$ \\
\hline Lung & 14 & 0.05 & 0.04 & $0 \cdot 01-0 \cdot 16$ & 15 & 0.06 & 0.04 & $0 \cdot 02-0 \cdot 14$ \\
\hline \multirow[t]{2}{*}{ Heart } & 14 & 0.04 & 0.02 & $0.01-0.09$ & 15 & $0 \cdot 16$ & $0 \cdot 33$ & $0 \cdot 01-1 \cdot 30$ \\
\hline & & & & & 14 & 0.08 & 0.09 & $0 \cdot 01-0 \cdot 37$ \\
\hline \multirow[t]{2}{*}{ Aorta } & 11 & 0.17 & $0 \cdot 24$ & $0 \cdot 03-0 \cdot 87$ & 9 & $0 \cdot 27$ & $0 \cdot 34$ & $0 \cdot 02-1 \cdot 10$ \\
\hline & 10 & $0 \cdot 10$ & 0.08 & $0 \cdot 03-0 \cdot 25$ & 8 & $0 \cdot 17$ & $0 \cdot 14$ & $0.02-0.40$ \\
\hline Muscle & 14 & 0.07 & 0.08 & $0.01-0.28$ & 15 & $0 \cdot 14$ & $0 \cdot 13$ & $0.02-0.48$ \\
\hline Fat & 9 & $0 \cdot 14$ & $0 \cdot 12$ & $0 \cdot 02-0 \cdot 34$ & 6 & $0 \cdot 23$ & 0.20 & $0.05-0.55$ \\
\hline \multirow{2}{*}{ Skin } & 13 & $0 \cdot 24$ & 0.51 & $0 \cdot 02-1 \cdot 90$ & 14 & $0 \cdot 46$ & 0.40 & $0 \cdot 02-1 \cdot 70$ \\
\hline & 12 & 0.11 & $0 \cdot 11$ & $0.02-0.39$ & & & & \\
\hline Dense connective tissue & 10 & 0.06 & 0.04 & $0 \cdot 02-0 \cdot 13$ & 13 & $0 \cdot 21$ & $0 \cdot 15$ & $0.01-0.48$ \\
\hline \multirow{2}{*}{\multicolumn{9}{|c|}{ Gastrointestinal tract: }} \\
\hline & & & & & & & & \\
\hline Stomach & 14 & $0 \cdot 10$ & $0 \cdot 10$ & $0 \cdot 03-0 \cdot 32$ & 15 & $0 \cdot 16$ & $0 \cdot 12$ & 0.03 .0 .47 \\
\hline Caecum & 12 & $0 \cdot 15$ & $0 \cdot 13$ & $0.01-0.40$ & 11 & 0.37 & $0 \cdot 33$ & $0 \cdot 07-1 \cdot 10$ \\
\hline Midgut & 14 & $0 \cdot 10$ & 0.06 & $0 \cdot 02-0 \cdot 24$ & 15 & $0 \cdot 19$ & $0 \cdot 11$ & $0.05-0 \cdot 37$ \\
\hline
\end{tabular}

Figures in italics exclude highest values. 
that home neglect may have contributed towards increased exposure to lead.

Table 1 shows the combined results of all the infants in the two groups. For the most part only small differences were found in the mean concentrations of lead in the individual tissues in the two groups of infants. The bones contained the higher concentrations but at a much lower level than in adults, and there was little or no difference in lead concentrations among types of bone. The lead found in the infant ribs was ten times less than the mean concentration found in adult ribs, and in infant tibia and calvaria was 30-40 times less than in the same bones in adults (table 4). Most of the infant soft tissues showed mean concentrations of lead that were either less than or equivalent to adult values. The adrenal gland, muscle, fat, and skin had marginally higher values, but the liver, spleen, kidney, brain, lung, aorta, dense connective tissue, and cartilage contained concentrations of lead that were lower than those found in these same tissues in adults. The concentrations in the pancreas, thyroid, and gastrointestinal tract equated with adult values. The mean concentration of lead in the blood of both groups of infants was $0.56 \mu \mathrm{mol} / 1(11.5 \mu \mathrm{g} / 100 \mathrm{ml})$.
Table 2 shows the results of comparing the mean concentrations of lead in the tissues of the 14 stillbirths with those in the 15 live births aged less than 12 days. In nearly every tissue, except for the thymus gland, the mean concentrations of lead were clearly lower in the stillbirths than in the live births, the difference between the two groups being confirmed by analysis of variance at a level of significance of $95 \%$; this finding does not support a hypothesis that might suggest lead as a causal factor in intrauterine death.

Table 3 shows the mean concentrations of lead in the tissues of 18 children aged 1-9 years of both sexes. Causes of death were mostly accidental but included infections, asthma, epilepsy, cerebral haemorrhage, and uraemia from hydronephrosis. The 9-year-old boy who died from a cerebral haemorrhage was hypertensive, mentally retarded since infancy, and suffered from idiopathic hypercalcaemia for which he had been treated with a low calcium diet. ${ }^{1}$ The concentrations of lead in his liver and kidneys were raised, compared with those in the same tissues in the other children in the group, but in the remainder of his tissues, including bone, the concentrations were comparable.

Table 3 Concentrations of lead in tissues of children (ppm wet weight)

\begin{tabular}{|c|c|c|c|c|c|c|c|c|c|c|c|c|}
\hline \multirow[t]{2}{*}{ Tissue } & \multicolumn{4}{|c|}{$1-5$ years } & \multicolumn{4}{|c|}{$6-9$ years } & \multicolumn{4}{|c|}{$1-9$ years } \\
\hline & $N o$ & Mean & $S D$ & Range & No & Mean & $S D$ & Range & No & Mean & $S D$ & Range \\
\hline \multicolumn{13}{|l|}{ Blood } \\
\hline $\begin{array}{l}(\mu \mathrm{mol} / \mathrm{l}) \\
(\mu \mathrm{g} / 100 \mathrm{ml})\end{array}$ & 8 & $\begin{array}{c}0.91 \\
18 \cdot 8\end{array}$ & $\begin{array}{l}0 \cdot 56 \\
11 \cdot 5\end{array}$ & $\begin{array}{l}0 \cdot 39-1 \cdot 93 \\
8 \cdot 0-40 \cdot 0\end{array}$ & 8 & $\begin{array}{l}0 \cdot 60 \\
12 \cdot 5\end{array}$ & $\begin{array}{l}0 \cdot 16 \\
3 \cdot 4\end{array}$ & $\begin{array}{l}0 \cdot 24-0 \cdot 82 \\
5 \cdot 0-17 \cdot 0\end{array}$ & 16 & $\begin{array}{l}0.75 \\
15 \cdot 6\end{array}$ & $\begin{array}{l}0.43 \\
8.8\end{array}$ & $\begin{array}{l}0 \cdot 24-1 \cdot 93 \\
5 \cdot 0-40 \cdot 0\end{array}$ \\
\hline \multicolumn{13}{|l|}{ Bone: } \\
\hline Rib & 9 & $2 \cdot 64$ & $1 \cdot 60$ & $0 \cdot 34-5 \cdot 50$ & 9 & 2.05 & $1 \cdot 41$ & $0 \cdot 01-3 \cdot 90$ & 18 & $2 \cdot 34$ & $1 \cdot 50$ & $0 \cdot 01-5 \cdot 50$ \\
\hline Tibia & 9 & $2 \cdot 79$ & $1 \cdot 84$ & $0 \cdot 37-6 \cdot 20$ & 8 & $2 \cdot 73$ & $2 \cdot 25$ & $0 \cdot 16-5 \cdot 50$ & 17 & $2 \cdot 76$ & $1 \cdot 98$ & $0 \cdot 16-6 \cdot 20$ \\
\hline Calvaria & 8 & $3 \cdot 04$ & $2 \cdot 03$ & $0 \cdot 51-6 \cdot 50$ & 8 & 3.79 & $2 \cdot 61$ & $0 \cdot 49-6 \cdot 70$ & 16 & $3 \cdot 41$ & $2 \cdot 29$ & $0 \cdot 49-6 \cdot 70$ \\
\hline Liver & 9 & 0.65 & $0 \cdot 29$ & $0 \cdot 14-1 \cdot 03$ & 9 & 0.74 & 0.47 & $0.05-1 \cdot 40$ & 18 & 0.69 & $0 \cdot 38$ & $0 \cdot 05-1 \cdot 40$ \\
\hline Spleen & 9 & $0 \cdot 12$ & 0.06 & $0 \cdot 03-0 \cdot 23$ & 8 & $0 \cdot 12$ & 0.05 & $0 \cdot 06-0 \cdot 22$ & 17 & $0 \cdot 12$ & 0.05 & $0.03-0.23$ \\
\hline \multicolumn{13}{|l|}{ Kidney: } \\
\hline $\begin{array}{l}\text { Cortex } \\
\text { Medulla }\end{array}$ & 9 & 0.58 & $0 \cdot 29$ & $0 \cdot 14-1 \cdot 20$ & 8 & 0.55 & $0 \cdot 32$ & $0 \cdot 13-1 \cdot 05$ & 17 & 0.56 & $0 \cdot 29$ & $0 \cdot 13-1 \cdot 20$ \\
\hline $\begin{array}{l}\text { Medulla } \\
\text { Combined }\end{array}$ & 8 & 0.37 & $0 \cdot 21$ & $0.07-0.73$ & 8 & $0 \cdot 37$ & $0 \cdot 24$ & 0.09-0.80 & 16 & $0 \cdot 37$ & $0 \cdot 22$ & $\begin{array}{l}0.07-0 \cdot 80 \\
0.11-0.93\end{array}$ \\
\hline \multirow{2}{*}{ Adrenal } & $\begin{array}{l}9 \\
9\end{array}$ & 0.49 & $0 \cdot 24$ & $0 \cdot 11-0 \cdot 89$ & 8 & 0.46 & 0.28 & $0 \cdot 11-0.93$ & 17 & 0.48 & 0.26 & $\begin{array}{l}0.11-0.93 \\
0.09-1 \cdot 20\end{array}$ \\
\hline & $\begin{array}{l}9 \\
7\end{array}$ & $\begin{array}{l}0 \cdot 37 \\
0 \cdot 18\end{array}$ & $\begin{array}{l}0.39 \\
0.08\end{array}$ & $\begin{array}{l}0.05-1 \cdot 20 \\
0.05-0 \cdot 25\end{array}$ & 7 & $0 \cdot 21$ & $0 \cdot 10$ & $0.09-0.32$ & $\begin{array}{l}16 \\
14\end{array}$ & $\begin{array}{c}0.30 \\
0 \cdot 20\end{array}$ & $\begin{array}{c}0.30 \\
0.09\end{array}$ & $\begin{array}{l}0 \cdot 09-1 \cdot 20 \\
0 \cdot 09-0 \cdot 32\end{array}$ \\
\hline Pancreas & 9 & $0 \cdot 31$ & $0 \cdot 13$ & $0 \cdot 17-0.58$ & 9 & $0 \cdot 34$ & $0 \cdot 17$ & $0.08-0.68$ & 18 & 0.32 & $0 \cdot 15$ & $0.08-0.68$ \\
\hline Thymus & 3 & 0.08 & 0.03 & $0.05-0 \cdot 10$ & 1 & 0.08 & & & 4 & 0.08 & 0.02 & $0 \cdot 05-0 \cdot 10$ \\
\hline Thyroid & 9 & 0.26 & $0 \cdot 23$ & $0.04-0.80$ & 8 & $0 \cdot 16$ & 0.07 & $0.05 \cdot 0 \cdot 24$ & 17 & 0.21 & $0 \cdot 18$ & $0 \cdot 04-0.80$ \\
\hline Brain cortex & 9 & 0.05 & 0.03 & $0.02-0.09$ & 9 & 0.08 & 0.07 & $0 \cdot 03-0 \cdot 21$ & 18 & 0.07 & 0.05 & $0.02-0.21$ \\
\hline Lung & 9 & $0 \cdot 16$ & $0 \cdot 11$ & $0.05-0.36$ & 9 & $0 \cdot 22$ & $0 \cdot 18$ & $0.08-0.59$ & 18 & $0 \cdot 19$ & $0 \cdot 15$ & $0.05-0.59$ \\
\hline Heart & 9 & 0.07 & 0.03 & $0 \cdot 03-0 \cdot 11$ & 8 & $0 \cdot 10$ & 0.06 & $0 \cdot 02-0 \cdot 17$ & 17 & 0.08 & 0.05 & $0 \cdot 02-0 \cdot 17$ \\
\hline \multirow[t]{2}{*}{ Aorta } & 9 & 0.26 & 0.33 & $0 \cdot 04-1 \cdot 10$ & 8 & $0 \cdot 24$ & $0 \cdot 12$ & $0.07-0.46$ & 17 & $0 \cdot 25$ & $0 \cdot 24$ & $0 \cdot 04-1 \cdot 10$ \\
\hline & 8 & $0 \cdot 15$ & 0.09 & $0 \cdot 04-0 \cdot 31$ & & & & & 16 & $0 \cdot 20$ & $0 \cdot 11$ & $0.04-0.46$ \\
\hline \multirow[t]{2}{*}{ Muscle } & 8 & 0.09 & $0 \cdot 10$ & $0 \cdot 02-0 \cdot 30$ & 8 & 0.08 & 0.05 & $902-0 \cdot 15$ & 16 & 0.08 & 0.07 & $0 \cdot 02-0 \cdot 30$ \\
\hline & 7 & 0.06 & 0.05 & $0.02-0 \cdot 16$ & & & & & 15 & 0.07 & 0.05 & $0 \cdot 02-0 \cdot 16$ \\
\hline Fat & 8 & 0.29 & $0 \cdot 25$ & $0.02-0.74$ & 7 & $0 \cdot 19$ & 0.08 & $0 \cdot 10-0 \cdot 30$ & 15 & $0 \cdot 24$ & $0 \cdot 19$ & $0.02-0.74$ \\
\hline \multirow[t]{2}{*}{ Skin } & 8 & $0 \cdot 37$ & $0 \cdot 24$ & $0.04-0.69$ & 7 & $0 \cdot 50$ & 0.62 & $0 \cdot 07-1 \cdot 80$ & 15 & 0.43 & 0.44 & $0 \cdot 04-1 \cdot 80$ \\
\hline & & & & & 6 & $0 \cdot 28$ & 0.25 & $0 \cdot 07-0 \cdot 70$ & 14 & $0 \cdot 33$ & $0 \cdot 24$ & $0 \cdot 04-0 \cdot 70$ \\
\hline Dense connective tissue & 5 & 0.08 & $0 \cdot 04$ & $0 \cdot 03-0 \cdot 15$ & 6 & $0 \cdot 26$ & 0.22 & $0 \cdot 02-0.57$ & 11 & $0 \cdot 18$ & $0 \cdot 18$ & $0 \cdot 02-0 \cdot 57$ \\
\hline Cartilage & 8 & $0 \cdot 23$ & $0 \cdot 15$ & $0.06-0.50$ & 8 & $0 \cdot 16$ & $0 \cdot 15$ & $0.05-0.44$ & 16 & $0 \cdot 20$ & $0 \cdot 15$ & $0.05-0.44$ \\
\hline \multicolumn{13}{|l|}{ Gastrointestinal tract: } \\
\hline Stomach & 8 & $0 \cdot 11$ & 0.05 & $0 \cdot 03-0 \cdot 20$ & 8 & 0.08 & 0.05 & $0 \cdot 05-0 \cdot 20$ & 16 & $0 \cdot 10$ & 0.05 & $0 \cdot 03-0 \cdot 20$ \\
\hline Caecum & 8 & $0 \cdot 12$ & 0.07 & $0.04-0.25$ & 8 & $0 \cdot 11$ & 0.06 & $0 \cdot 04-0 \cdot 21$ & 16 & $0 \cdot 11$ & 0.07 & $0 \cdot 04-0 \cdot 25$ \\
\hline Midgut & 8 & $0 \cdot 17$ & $0 \cdot 15$ & $0.04-0.52$ & 8 & $0 \cdot 18$ & $0 \cdot 14$ & $0.05-0.51$ & 16 & $0 \cdot 17$ & $0 \cdot 14$ & $0.04-0.52$ \\
\hline
\end{tabular}

Figures in italics exclude highest values. 
Table 4 Concentrations of lead in tissues of older children and adults ( $p p m$ wet weight)

\begin{tabular}{|c|c|c|c|c|c|c|c|c|c|c|c|c|}
\hline \multirow[t]{2}{*}{ Tissue } & \multicolumn{4}{|c|}{ Children, $11-16$ years } & \multicolumn{4}{|c|}{ Men } & \multicolumn{4}{|c|}{ Women } \\
\hline & No & Mean & $S D$ & Range & No & Mean & $S D$ & Range & No & Mean & $S D$ & Range \\
\hline \multicolumn{13}{|l|}{ Blood } \\
\hline $\begin{array}{l}(\mu \mathrm{mol} / \mathrm{l}) \\
(\mu \mathrm{g} / 100 \mathrm{ml})\end{array}$ & 5 & $\begin{array}{l}0 \cdot 79 \\
16 \cdot 4\end{array}$ & $\begin{array}{l}0 \cdot 40 \\
8 \cdot 2\end{array}$ & $\begin{array}{l}0 \cdot 34-1 \cdot 35 \\
7 \cdot 0-28 \cdot 0\end{array}$ & 53 & $\begin{array}{l}0.97 \\
20 \cdot 0\end{array}$ & $\begin{array}{l}0 \cdot 58 \\
12 \cdot 0\end{array}$ & $\begin{array}{l}0 \cdot 15-3 \cdot 82 \\
3 \cdot 0-79 \cdot 0\end{array}$ & 30 & $\begin{array}{c}0.77 \\
16.0\end{array}$ & $\begin{array}{c}0.48 \\
10.0\end{array}$ & $\begin{array}{l}0 \cdot 19-1 \cdot 98 \\
4 \cdot 0-41 \cdot 0\end{array}$ \\
\hline \multicolumn{13}{|l|}{ Bone: } \\
\hline Rib & 6 & $2 \cdot 05$ & 0.97 & $1 \cdot 00-3 \cdot 30$ & 60 & $8 \cdot 85$ & $5 \cdot 81$ & $0 \cdot 90-28 \cdot 50$ & 36 & $6 \cdot 77$ & $5 \cdot 08$ & $0 \cdot 85-22 \cdot 60$ \\
\hline Tibia & 5 & $2 \cdot 68$ & 1.06 & $1 \cdot 50-4 \cdot 40$ & 60 & $23 \cdot 40$ & $15 \cdot 96$ & $3 \cdot 00-73 \cdot 00$ & 36 & $15 \cdot 99$ & $12 \cdot 49$ & $1 \cdot 50-48 \cdot 00$ \\
\hline Calvaria & $\begin{array}{l}5 \\
4\end{array}$ & $\begin{array}{l}4 \cdot 01 \\
2 \cdot 27\end{array}$ & $\begin{array}{l}3.28 \\
1.99\end{array}$ & $\begin{array}{l}0.43-9.00 \\
0.43-4.90\end{array}$ & 31 & $20 \cdot 17$ & $16 \cdot 00$ & $3 \cdot 90-79 \cdot 00$ & 17 & $16 \cdot 46$ & 13.08 & $5 \cdot 00-54 \cdot 20$ \\
\hline Liver & 6 & 0.57 & $0 \cdot 26$ & $0 \cdot 26-0.92$ & 58 & $1 \cdot 03$ & 0.62 & $0 \cdot 18-3 \cdot 13$ & 36 & 0.66 & $0 \cdot 38$ & $0 \cdot 19-1 \cdot 72$ \\
\hline Spleen & 5 & $0 \cdot 14$ & 0.06 & $0 \cdot 05-0 \cdot 21$ & $\begin{array}{l}59 \\
57\end{array}$ & $\begin{array}{l}0 \cdot 23 \\
0 \cdot 20\end{array}$ & $\begin{array}{l}0.25 \\
0.15\end{array}$ & $\begin{array}{l}0.03-1.43 \\
0.03-0.82\end{array}$ & $\begin{array}{l}34 \\
32\end{array}$ & $\begin{array}{l}0 \cdot 21 \\
0 \cdot 16\end{array}$ & $\begin{array}{l}0.26 \\
0.09\end{array}$ & $\begin{array}{l}0.04-1 \cdot 40 \\
0.04-0.39\end{array}$ \\
\hline \multicolumn{13}{|l|}{ Kidney: } \\
\hline Cortex & 6 & 0.55 & $0 \cdot 24$ & $0 \cdot 34-1 \cdot 00$ & 59 & $0 \cdot 78$ & $0 \cdot 38$ & $0 \cdot 15-1 \cdot 85$ & 35 & 0.55 & 0.39 & $0 \cdot 10-2 \cdot 20$ \\
\hline Medulla & 6 & $0 \cdot 37$ & $0 \cdot 14$ & $0 \cdot 24-0.65$ & 59 & 0.50 & $0 \cdot 25$ & $0 \cdot 13-1 \cdot 46$ & 36 & $0 \cdot 38$ & $0 \cdot 19$ & $0 \cdot 11 \cdot 0.97$ \\
\hline Combined & 6 & $0 \cdot 46$ & $0 \cdot 19$ & $0.33-0.83$ & 59 & 0.64 & 0.32 & $0 \cdot 14-1 \cdot 40$ & 36 & 0.46 & $0 \cdot 29$ & $0 \cdot 11-1 \cdot 31$ \\
\hline Adrenal & 5 & $0 \cdot 13$ & 0.09 & $0 \cdot 04-0 \cdot 27$ & 54 & $0 \cdot 15$ & $0 \cdot 11$ & $0.01-0.62$ & 27 & $0 \cdot 17$ & 0.11 & $0.05-0.48$ \\
\hline Pancreas & 6 & $0 \cdot 34$ & $0 \cdot 15$ & $0 \cdot 19-0 \cdot 61$ & 58 & 0.37 & $0 \cdot 26$ & $0.09-1.42$ & 36 & $0 \cdot 27$ & $0 \cdot 17$ & $0.11-0.95$ \\
\hline \multirow[t]{2}{*}{ Thyroid } & 5 & $0 \cdot 16$ & 0.07 & $0 \cdot 07-0 \cdot 26$ & 54 & $0 \cdot 19$ & 0.23 & $0.05-1.45$ & 30 & $0 \cdot 21$ & 0.30 & $0.04-1.73$ \\
\hline & & & & & 52 & $0 \cdot 15$ & 0.09 & $0.05-0.41$ & 29 & $0 \cdot 15$ & $0 \cdot 10$ & $0.04-0.55$ \\
\hline \multirow[t]{2}{*}{ Brain cortex } & 6 & 0.06 & $0 \cdot 04$ & $0 \cdot 02-0 \cdot 13$ & 58 & $0 \cdot 10$ & $0 \cdot 14$ & $0.02-0.78$ & 34 & $0 \cdot 12$ & $0 \cdot 15$ & $0.01-0.67$ \\
\hline & & & & & 56 & 0.08 & 0.05 & $0 \cdot 02-0 \cdot 27$ & 32 & 0.09 & 0.08 & $0 \cdot 01-0 \cdot 34$ \\
\hline Lung & 6 & $0 \cdot 14$ & 0.07 & $0 \cdot 07-0 \cdot 25$ & 59 & $0 \cdot 22$ & $0 \cdot 11$ & $0.05-0.59$ & 36 & 0.22 & $0 \cdot 12$ & $0.04-0.55$ \\
\hline Heart & 6 & 0.09 & 0.07 & $0 \cdot 03-0 \cdot 18$ & 59 & 0.07 & 0.05 & $0.01-0.30$ & 36 & 0.08 & 0.06 & $0 \cdot 02-0 \cdot 31$ \\
\hline \multirow[t]{2}{*}{ Aorta } & 6 & $1 \cdot 89$ & 3.93 & $0 \cdot 04-9 \cdot 90$ & 32 & $2 \cdot 56$ & $3 \cdot 49$ & $0 \cdot 21-17 \cdot 20 \mathrm{~A}$ & A 16 & $1 \cdot 17$ & $1 \cdot 23$ & $0 \cdot 09-4 \cdot 20$ \\
\hline & 5 & $0 \cdot 29$ & $0 \cdot 30$ & $0.04-0.65$ & 42 & $1 \cdot 82$ & $2 \cdot 47$ & $0 \cdot 09-12 \cdot 70 \mathrm{~N}$ & NA 22 & $1 \cdot 70$ & $2 \cdot 64$ & $0.07-12 \cdot 20$ \\
\hline Muscle & 4 & 0.07 & 0.05 & $0 \cdot 02-0 \cdot 11$ & 35 & 0.05 & 0.04 & $0 \cdot 02-0 \cdot 23$ & 29 & 0.05 & 0.03 & $0 \cdot 01-0 \cdot 15$ \\
\hline \multirow[t]{2}{*}{ Fat } & 4 & $0 \cdot 21$ & $0 \cdot 26$ & $0.03-0.58$ & 23 & 0.08 & 0.08 & $0 \cdot 01-0.40$ & 20 & 0.06 & 0.04 & $0 \cdot 02-0 \cdot 16$ \\
\hline & 3 & 0.09 & 0.09 & $0 \cdot 03-0 \cdot 19$ & & & & & & & & \\
\hline Skin & 4 & $0 \cdot 34$ & $0 \cdot 25$ & $0 \cdot 15-0 \cdot 70$ & 26 & $0 \cdot 19$ & $0 \cdot 14$ & $0 \cdot 01-0 \cdot 60$ & 20 & $0 \cdot 15$ & $0 \cdot 11$ & $0.03-0.42$ \\
\hline \multirow[t]{2}{*}{ Dense connective tissue } & 4 & $0 \cdot 32$ & 0.43 & $0 \cdot 09-1 \cdot 00$ & 16 & $0 \cdot 33$ & $0 \cdot 29$ & $0.03-0.90$ & 11 & $0 \cdot 37$ & $0 \cdot 23$ & $0 \cdot 10-0 \cdot 86$ \\
\hline & 3 & $0 \cdot 14$ & 0.06 & $0 \cdot 09-0 \cdot 20$ & & & & & & & & \\
\hline \multicolumn{10}{|l|}{ Gastrointestinal tract: } & & & $0 \cdot 08-1 \cdot 75$ \\
\hline Stomach & 4 & 0.09 & 0.04 & $0 \cdot 04-0 \cdot 14$ & 32 & 0.09 & 0.05 & $0.03-0.25$ & 26 & $0 \cdot 11$ & $0 \cdot 10$ & $0.02-0.42$ \\
\hline Caecum & 4 & $0 \cdot 22$ & $0 \cdot 18$ & $0.06-0.47$ & 32 & 0.09 & 0.06 & $0 \cdot 03-0 \cdot 27$ & 27 & $0 \cdot 14$ & $0 \cdot 14$ & $0.02-0.68$ \\
\hline Midgut & 3 & $0 \cdot 14$ & 0.07 & $0 \cdot 06-0 \cdot 18$ & 31 & $0 \cdot 12$ & 0.06 & $0 \cdot 05-0 \cdot 32$ & 27 & $0 \cdot 12$ & $0 \cdot 10$ & $0.03-0.48$ \\
\hline
\end{tabular}

Figures in italics exclude highest values. $\mathbf{A}=$ Atheroma. $\mathbf{N A}=$ Non-atheroma.

The mean concentrations of lead in the bones of the group aged 1-9 years were about three times greater than in the infants aged up to 11 months. The mean concentrations in most of the soft tissues equated with adult values, except in the spleen, aorta, cartilage, and connective tissue, where the concentrations were lower, and in the adrenal gland, fat, and skin, where they were higher. Most of the soft tissue results were higher than in the infant group, and the mean blood lead concentration was 0.75 $\mu \mathrm{mol} / 1(15.6 \mu \mathrm{g} / 100 \mathrm{ml})$.

The group aged 1-9 was further divided into those aged 1-5, which would include any child prone to pica, and those aged 6-9 as a "postpica" group (table 3). No difference was observed in the lead concentrations in the body tissues in the two groups. The results showed a higher mean concentration of lead in the blood in the children aged 1-5, which was not reflected in their other body tissues. Possibly excretory mechanisms may have regulated the lead in their tissues at a low concentration or some of the blood samples may have been contaminated. Since evidence of history of pica was not sought and in view of the small numbers in each group any explanation for the blood lead difference can only be speculative.

Table 4 shows the concentrations of lead found in the tissues of the small group of six boys aged 11-16. Causes of death were cerebral haemorrhage associated with a cerebral tumour, meningococcal septicaemia in a child with congenital heart disease, pneumococcal meningitis, viral pneumonia in an ideopathic epileptic, and skull fracture with a subdural haematoma. In the last case, a boy of 13 , lead poisoning was suspected as he had been burning lead batteries and for three days had experienced headaches before he went into coma before his death. The concentrations of lead found in his tissues were not excessive, and the cause of death was almost certainly accidental because, although there was no recorded history of trauma, at necropsy he was found to have a hairline fracture of the skull with a subdural haematoma.

The mean concentrations of lead in the various types of bones of the children aged 11-16 did not differ to any material extent from those found in the 


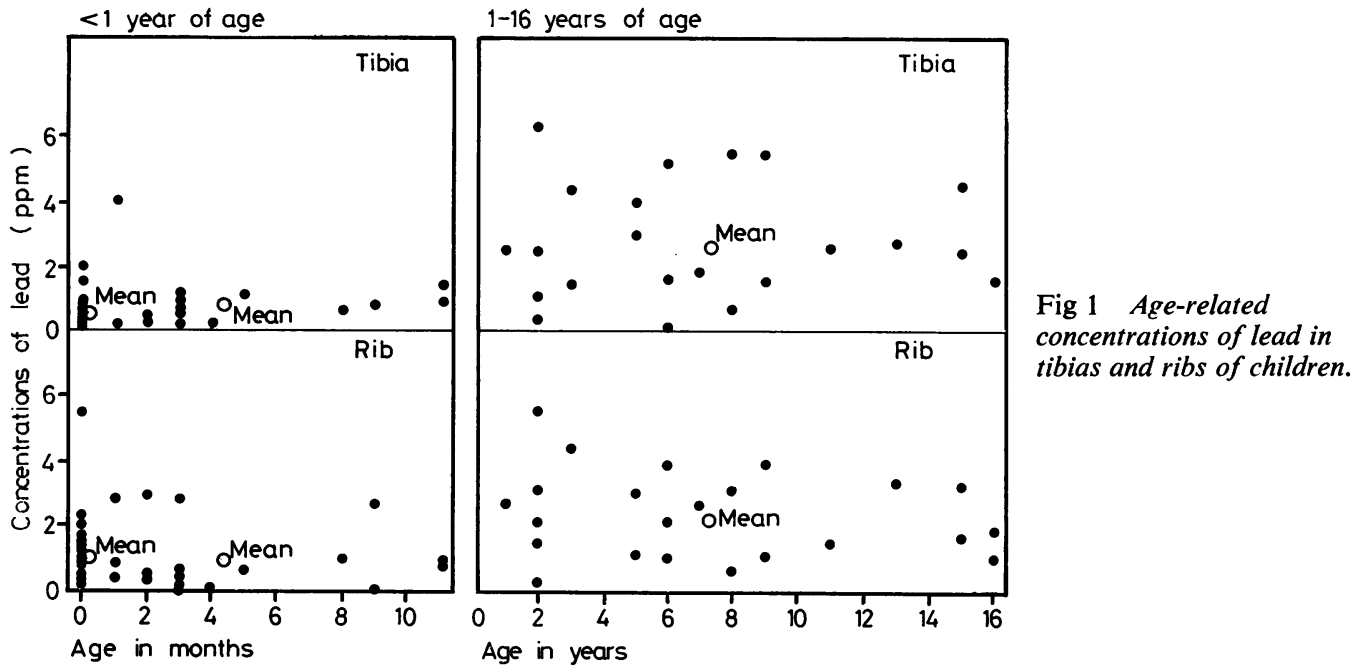

bones of children aged 1-9. The differences in lead concentrations seen in different types of adult bones were not apparent in the group aged 11-16; also the mean concentrations were three to seven times less than those observed in the bones of women (table 4). Although the mean concentrations were about three times greater than in the infant group, there was no clear evidence of increase of lead in the bones with age in the older group of children (fig 1). Thus bone probably does not accumulate lead to any great extent in either sex until after the growing phase has ceased, at about the end of the second decade of life.

The concentrations of lead in the soft tissues of the group aged 11-16 were similar to those found in the group of children aged 1-9 (table 3) and did not differ substantially from female adult values (table 4). Owing to age-related regression no samples of the thymus gland were obtained after the first decade of life. The mean concentration of lead in the blood of the group aged $11-16$ was $0 \cdot 79 \mu \mathrm{mol} / 1(16.4 \mu \mathrm{g} / 100 \mathrm{ml})$, which corresponded very closely to the female adult mean value of $0.77 \mu \mathrm{mol} / 1(16.0 \mu \mathrm{g} / 100 \mathrm{ml})$.

The mean concentrations of lead in the bones of infants aged under 1 were compared with those of children aged 1-16, as well as with those of men and women, on a wet-weight and ash-weight basis of measurement. The results showed higher values for ash-weight than for wet-weight measurement, as would be expected and has been reported in other studies. ${ }^{3-5}$ In the infant age group the ribs contained higher concentrations of lead than the tibia and calvaria, but this did not apply in the older children.

The ratios between the lead concentrations in the various types of bone in terms of wet weight and ashed weight were similar for the group aged 1-16 and the women. The ratio in the ribs of both groups was the same at 2.9 ; in the tibia it was 1.6 and 1.4 respectively and in the calvaria 1.5 and 1.3 . The ratios in the men were 3.7 for rib, 1.6 for tibia, and 1.4 for calvaria.

As might be expected, due to the lower mineral content in their bones the ratios were greater in the infant group at 5.1 for rib, 2.8 for tibia, and 2.3 for calvaria. If, however, the ratios are compared proportionately they become similar to the other age groups at 3.0 for rib, 1.6 for tibia, and 1.4 for calvaria. It might have been expected for there to have been no ratio differences in the bones of the infants, in contrast to adults and older children, by reason of uniformity of haemopoietic function and vascularity in the infant skeleton. That this was not so suggests that the pattern of deposition of lead in the bones of infants may not be greatly dissimilar from that in adults.

In figs 2-5 the distributions of the results in some of the tissues of the stillbirths and in the infants aged under 1 are compared on wet-weight measurement with those of children aged 1-16. In some of the infant tissues the results were skewed towards low concentrations of lead, whereas in the children aged 1-16 they were more evenly distributed across a wider range of concentrations. This implies that lead concentrations rose with age but in some tissues reached a plateau in the group aged 1-16. It is known, however, that in the case of the bones and aorta concentrations of lead continue to increase with age. ${ }^{6}$

The kidney and the liver (fig 3) showed a similar pattern of distribution to the bones (fig 2) in each 


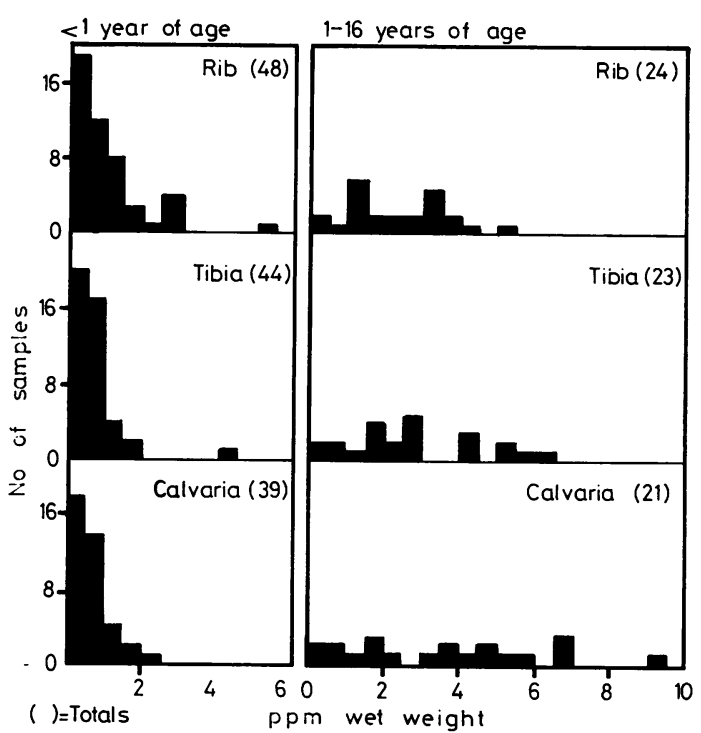

Fig 2 Distribution of results in ribs, tibias, and calvarias of children.

age group, albeit at different concentrations, as also did the lung (fig 4). In the fat and brain (fig 4) and the aorta, muscle, and heart (fig 5) the concentrations of lead and the patterns of distribution varied, but were such as to suggest no obvious difference between the two age groups of children. Cartilage, dense connective tissue, and skin in each age group showed similar patterns of distribution of lead to the tissues shown in figs 2 and 3 and in the lung (fig 4),

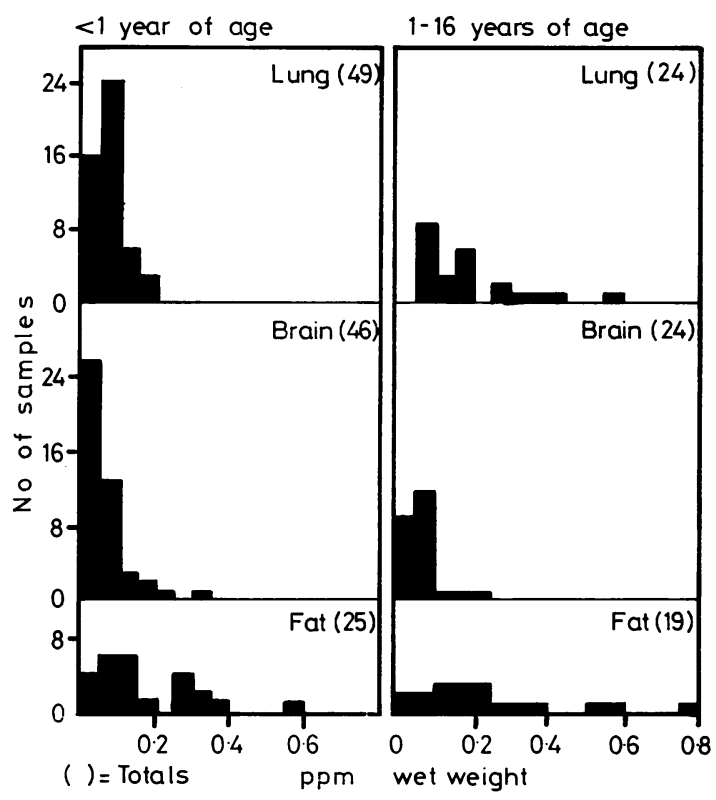

Fig 4 Distribution of results in lungs, brains, and fat of children.

whereas the endocrine glands, blood, spleen, and the gastrointestinal tract showed patterns of distribution similar to the fat and brain (fig 4) and to the tissues (fig 5).

Irrespective of age the blood and the spleen showed similar distribution configurations, as also did the endocrine glands, but the brain and fat, which might have been expected to be similar,

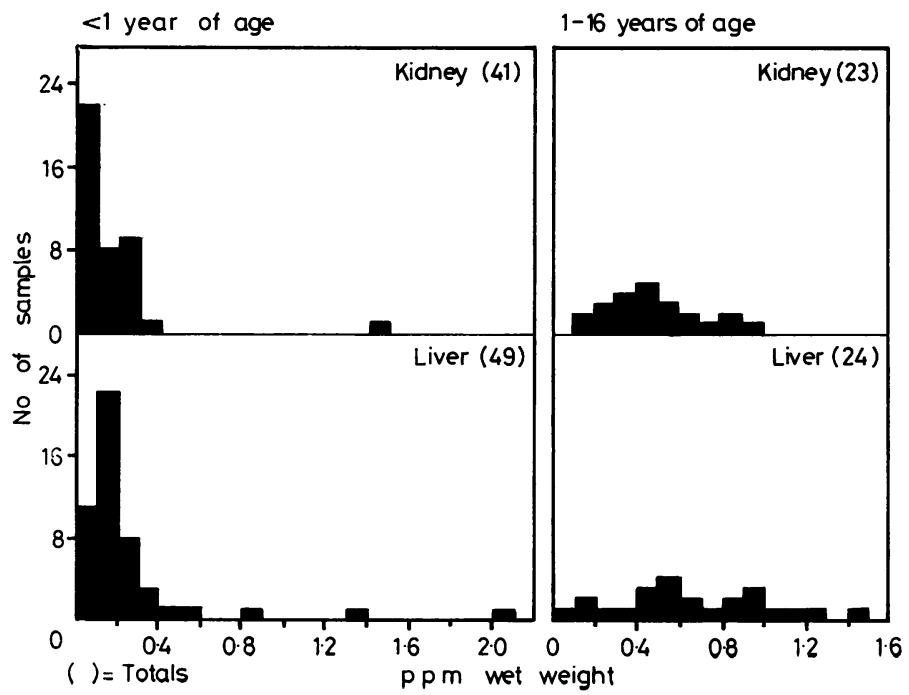

Fig 3 Distribution of results in kidneys and livers of children. 


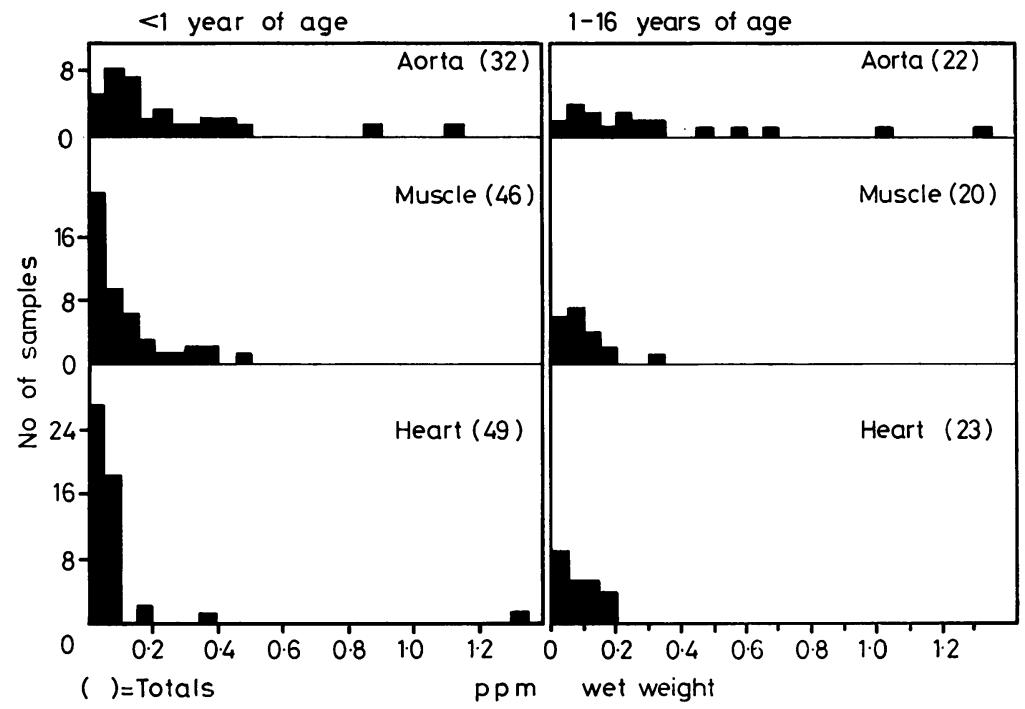

Fig 5 Distribution of results in aortas, muscles, and hearts of children.

differed in that the concentrations of lead were less in brain than in fat, suggesting a possible influence of the blood-brain barrier. There was also a variable distribution of lead in the gastrointestinal tract, but the muscle and heart were similar and differed from the aorta, in which the distribution of results was more evenly spread over a wider range of lead concentrations.

Table 5 shows the results of assessing the concentrations of lead in the tissues of the infant group of children, ranging from stillbirth to 11 months of age, for potential differences by sex. Marginally higher concentrations were observed in the liver, spleen, kidney, thymus gland, lung, and heart in the girls, but the boys showed higher concentrations in fat and skin. The differences were not considered to be of significant proportions.

To determine whether there was a time-related difference, the stillbirths and those infants aged under 1 year were assessed in groups to correspond to the years in which the tissue samples were collected. The results indicated a close correlation for the years 1966-8 and 1979. No samples were obtained between 1968 and 1975, but in some of the tissues analysed between 1975 and 1978 (such as the spleen, kidney, endocrine glands, aorta, skin, and gastrointestinal tract) the average concentrations of lead were found to be higher than in the years before and after this period. The differences were small, as also were the numbers of samples obtained in each year, at less than 10 per tissue. Within the framework of the data there was no clear evidence to suggest that overall exposure to lead had altered in the course of a time-span extending over more than a decade.

\section{Comparison with other studies}

The number of studies published on the lead content in the tissues of children have been relatively few.

\section{BONES}

Barth ${ }^{7}$ found lower concentrations of lead on ash weight in the bones of 10 infants of average age 4 months than in adult bones, which did not differ substantially from the results reported here.

Weyrauch and Muller ${ }^{8}$ and Grandjean ${ }^{9}$ found the concentrations of lead in the vertebrae of children to be about half those of adult values, whereas Holtzman et al ${ }^{10}$ found the concentrations to be one-fifth of adult values.

In the ribs of children two investigations showed concentrations of lead that were one-sixth of adult values ${ }^{1011}$ but higher concentrations, which approached those of adult values, were found by other investigators. ${ }^{12-15}$

The concentrations of lead found in the cortical bones of children by Krause ${ }^{16}$ and Weinig and Borner ${ }^{17}$ were considerably lower than those found in the cortical bones of adults. Higher concentrations, although still lower than those of adult values, were reported in some other studies. ${ }^{1013-15}$

As in the results reported in this study, Henderson and Inglis ${ }^{13}$ found little difference in the lead concentrations in trabecular and cortical bones in children, but Nusbaum et $a l^{15}$ and Holtzman et al ${ }^{10}$ found that the cortical bones contained the higher concentrations.

Hansmann and Perry ${ }^{12}$ found higher concentrations of lead in the ribs of fetuses than in those of 
Table 5 Concentrations of lead in tissues of male and female infants aged under 1 year (ppm wet weight)

\begin{tabular}{|c|c|c|c|c|c|c|c|c|}
\hline \multirow[t]{2}{*}{ Tissue } & \multicolumn{4}{|c|}{ Boys } & \multicolumn{4}{|c|}{ Girls } \\
\hline & No & Mean & $S D$ & Range & No & Mean & $S D$ & Range \\
\hline \multicolumn{9}{|l|}{ Blood } \\
\hline $\begin{array}{l}(\mu \mathrm{mol} / 1) \\
(\mu \mathrm{g} / 100 \mathrm{ml})\end{array}$ & 25 & $\begin{array}{c}0 \cdot 58 \\
12 \cdot 0\end{array}$ & $\begin{array}{l}0.32 \\
6.7\end{array}$ & $\begin{array}{l}0 \cdot 20-1 \cdot 21 \\
4 \cdot 2-25 \cdot 0\end{array}$ & 18 & $\begin{array}{c}0 \cdot 52 \\
10 \cdot 8\end{array}$ & $\begin{array}{l}0.31 \\
6 \cdot 5\end{array}$ & $\begin{array}{l}0 \cdot 05 \cdot 1 \cdot 35 \\
1 \cdot 1-28 \cdot 0\end{array}$ \\
\hline \multicolumn{9}{|l|}{ Bone: } \\
\hline Rib & 28 & 0.83 & 0.75 & $0 \cdot 03-2 \cdot 90$ & $\begin{array}{l}21 \\
20\end{array}$ & $\begin{array}{l}1 \cdot 06 \\
0 \cdot 84\end{array}$ & $\begin{array}{l}1 \cdot 30 \\
0.86\end{array}$ & $\begin{array}{l}0 \cdot 01-5 \cdot 40 \\
0 \cdot 01-2 \cdot 71\end{array}$ \\
\hline Tibia & 27 & 0.53 & 0.45 & $0 \cdot 02-1 \cdot 90$ & $\begin{array}{l}18 \\
17\end{array}$ & $\begin{array}{l}0.84 \\
0.65\end{array}$ & $\begin{array}{l}0 \cdot 86 \\
0.34\end{array}$ & $\begin{array}{l}0 \cdot 21-4 \cdot 00 \\
0 \cdot 21-1 \cdot 34\end{array}$ \\
\hline Calvaria & 23 & 0.62 & 0.49 & $0 \cdot 06-2 \cdot 10$ & 16 & 0.72 & 0.50 & $0 \cdot 22-1 \cdot 81$ \\
\hline Liver & 28 & $0 \cdot 14$ & 0.07 & $0.03-0.37$ & $\begin{array}{l}21 \\
19\end{array}$ & $\begin{array}{l}0 \cdot 38 \\
0 \cdot 24\end{array}$ & $\begin{array}{l}0.50 \\
0 \cdot 20\end{array}$ & $\begin{array}{l}0 \cdot 05-2 \cdot 10 \\
0 \cdot 05-0 \cdot 84\end{array}$ \\
\hline $\begin{array}{l}\text { Spleen } \\
\text { Kidney: }\end{array}$ & 27 & $0 \cdot 13$ & $0 \cdot 12$ & $0.03-0.54$ & 21 & $0 \cdot 17$ & $0 \cdot 16$ & $0.02-0.54$ \\
\hline Cortex & 22 & $0 \cdot 12$ & 0.09 & $0.01-0.36$ & $\begin{array}{l}15 \\
14\end{array}$ & $\begin{array}{l}0 \cdot 32 \\
0 \cdot 18\end{array}$ & $\begin{array}{l}0.56 \\
0.11\end{array}$ & $\begin{array}{l}0 \cdot 07-2 \cdot 30 \\
0 \cdot 07-0 \cdot 47\end{array}$ \\
\hline Medulla & 22 & 0.11 & 0.07 & $0.01-0.26$ & $\begin{array}{l}15 \\
14\end{array}$ & $\begin{array}{l}0 \cdot 17 \\
0 \cdot 14\end{array}$ & $\begin{array}{l}0 \cdot 15 \\
0 \cdot 11\end{array}$ & $\begin{array}{l}0 \cdot 01-0 \cdot 54 \\
0 \cdot 01-0 \cdot 31\end{array}$ \\
\hline Combined & 28 & $0 \cdot 11$ & 0.07 & $0.02-0.28$ & $\begin{array}{l}21 \\
20\end{array}$ & $\begin{array}{l}0 \cdot 20 \\
0 \cdot 13\end{array}$ & $\begin{array}{l}0.30 \\
0 \cdot 10\end{array}$ & $\begin{array}{l}0 \cdot 03-1 \cdot 42 \\
0.03-0.37\end{array}$ \\
\hline Adrenal & $\begin{array}{l}22 \\
21\end{array}$ & $\begin{array}{l}0 \cdot 24 \\
0 \cdot 17\end{array}$ & $\begin{array}{l}0 \cdot 34 \\
0 \cdot 15\end{array}$ & $\begin{array}{l}0.01-1 \cdot 60 \\
0 \cdot 01-0 \cdot 55\end{array}$ & $\begin{array}{l}17 \\
15\end{array}$ & $\begin{array}{l}0 \cdot 23 \\
0 \cdot 16\end{array}$ & $\begin{array}{l}0 \cdot 23 \\
0 \cdot 12\end{array}$ & $\begin{array}{l}0.03-0.82 \\
0.03-0.46\end{array}$ \\
\hline Pancreas & 16 & $0 \cdot 24$ & $0 \cdot 16$ & $0.02-0.53$ & $\begin{array}{l}15 \\
16 \\
15\end{array}$ & $\begin{array}{l}0 \cdot 33 \\
0 \cdot 18\end{array}$ & $\begin{array}{l}0.12 \\
0.60 \\
0.16\end{array}$ & $\begin{array}{l}0.05-0.40 \\
0.01-2.50 \\
0.01-0.56\end{array}$ \\
\hline Thymus & 16 & 0.08 & 0.06 & $0 \cdot 01-0 \cdot 21$ & $\begin{array}{l}14 \\
13\end{array}$ & $\begin{array}{l}0 \cdot 17 \\
0 \cdot 12\end{array}$ & $\begin{array}{l}0 \cdot 20 \\
0 \cdot 10\end{array}$ & $\begin{array}{l}0.02-0.78 \\
0.02-0.36\end{array}$ \\
\hline Thyroid & $\begin{array}{l}14 \\
12\end{array}$ & $\begin{array}{l}0 \cdot 27 \\
0 \cdot 10\end{array}$ & $\begin{array}{l}0.44 \\
0.07\end{array}$ & $\begin{array}{l}0 \cdot 01-1 \cdot 30 \\
0 \cdot 01-0 \cdot 22\end{array}$ & $\begin{array}{l}15 \\
14\end{array}$ & $\begin{array}{l}0 \cdot 20 \\
0 \cdot 14\end{array}$ & $\begin{array}{l}0.26 \\
0.09\end{array}$ & $\begin{array}{l}0.01-1 \cdot 10 \\
0.01-0 \cdot 27\end{array}$ \\
\hline Brain cortex & $\begin{array}{l}27 \\
26\end{array}$ & $\begin{array}{l}0.06 \\
0.05\end{array}$ & $\begin{array}{l}0.07 \\
0.04\end{array}$ & $\begin{array}{l}0.01-0.34 \\
0.01-0.18\end{array}$ & 19 & 0.06 & 0.06 & $0 \cdot 01-0.20$ \\
\hline Lung & 28 & 0.05 & 0.03 & $0 \cdot 01-0 \cdot 14$ & 21 & 0.08 & 0.04 & $0.02-0.18$ \\
\hline Heart & 28 & 0.05 & 0.07 & $0.01-0.37$ & 20 & $0 \cdot 12$ & $0 \cdot 28$ & $0 \cdot 01-1 \cdot 30$ \\
\hline Aorta & 27 & 0.04 & 0.02 & $0.01-0.09$ & 19 & 0.06 & 0.05 & $0 \cdot 01-0.19$ \\
\hline Aorta & $\begin{array}{l}18 \\
17\end{array}$ & $\begin{array}{l}0 \cdot 20 \\
0 \cdot 14\end{array}$ & $\begin{array}{l}0 \cdot 26 \\
0 \cdot 13\end{array}$ & $\begin{array}{l}0 \cdot 03-1 \cdot 10 \\
0 \cdot 03-0 \cdot 40\end{array}$ & $\begin{array}{l}16 \\
15\end{array}$ & $\begin{array}{l}0 \cdot 22 \\
0 \cdot 17\end{array}$ & $\begin{array}{l}0 \cdot 22 \\
0 \cdot 13\end{array}$ & $\begin{array}{l}0.02-0.87 \\
0.02-0.48\end{array}$ \\
\hline Muscle & 27 & 0.10 & 0.10 & $0 \cdot 01-0.36$ & $\begin{array}{l}19 \\
18\end{array}$ & $\begin{array}{l}0.09 \\
0.07\end{array}$ & $\begin{array}{l}0.11 \\
0.06\end{array}$ & $\begin{array}{l}0.01-0.48 \\
0.01-0.20\end{array}$ \\
\hline Fat & 12 & 0.18 & 0.16 & $0.03-0.55$ & 13 & $0 \cdot 14$ & $0 \cdot 11$ & $0 \cdot 01-0.34$ \\
\hline Skin & 24 & 0.31 & 0.39 & $0 \cdot 02-1.90$ & 17 & $0 \cdot 28$ & 0.42 & $0 \cdot 01-1 \cdot 70$ \\
\hline & 23 & $0 \cdot 24$ & $0 \cdot 19$ & $0.02-0.65$ & 16 & $0 \cdot 19$ & $0 \cdot 20$ & $0.01-0.63$ \\
\hline Dense connective tissue & 21 & $0 \cdot 14$ & 0.12 & $0 \cdot 01-0.48$ & 15 & $0 \cdot 11$ & $0 \cdot 12$ & $0.02-0.45$ \\
\hline Cartilage & 22 & $0 \cdot 15$ & $0 \cdot 13$ & $0.01-0.46$ & $\begin{array}{l}17 \\
16\end{array}$ & $\begin{array}{l}0 \cdot 27 \\
0 \cdot 15\end{array}$ & $\begin{array}{l}0 \cdot 50 \\
0 \cdot 15\end{array}$ & $\begin{array}{l}0 \cdot 02-2 \cdot 10 \\
0 \cdot 02-0 \cdot 50\end{array}$ \\
\hline Gastrointestinal tract: & & & & & & & & \\
\hline Stomach & 28 & $0 \cdot 11$ & 0.09 & $0 \cdot 01-0 \cdot 32$ & $\begin{array}{l}19 \\
18\end{array}$ & $\begin{array}{l}0 \cdot 10 \\
0.07\end{array}$ & $\begin{array}{l}0.10 \\
0.05\end{array}$ & $\begin{array}{l}0.03-0.47 \\
0.01-0.19\end{array}$ \\
\hline Caecum & $\begin{array}{l}22 \\
21\end{array}$ & $\begin{array}{l}0 \cdot 20 \\
0 \cdot 16\end{array}$ & $\begin{array}{l}0.25 \\
0 \cdot 16\end{array}$ & $\begin{array}{l}0.01-1 \cdot 10 \\
0 \cdot 01-0 \cdot 58\end{array}$ & $\begin{array}{l}17 \\
16\end{array}$ & $\begin{array}{l}0 \cdot 17 \\
0 \cdot 14\end{array}$ & $\begin{array}{l}0 \cdot 19 \\
0 \cdot 12\end{array}$ & $\begin{array}{l}0.01-0.75 \\
0.01-0.40\end{array}$ \\
\hline Midgut & 27 & $0 \cdot 13$ & 0.09 & $0 \cdot 02-0 \cdot 37$ & 19 & $0 \cdot 11$ & 0.09 & $0.02-0.36$ \\
\hline
\end{tabular}

Figures in italics exclude highest values.

children, but other studies ${ }^{18} 19$ have found low concentrations in fetal cortical bones that were not dissimilar from the results in infant bones reported here. Horiuchi et al $^{19}$ and Barltrop ${ }^{20}$ showed an increase in lead concentrations in the cortical bones with fetal maturity after the twentieth week of gestation. Casey and Robinson ${ }^{21}$ found mean dry-weight concentrations of lead in fetal vertebras which, on conversion to wet weight, were similar to the concentrations found in the bones in the infant group reported in this study.

Bryce-Smith et al $^{22}$ found mean concentrations of lead in the ribs of 26 stillbirths that were about nine times those found in the ribs of the stillbirths in this study; lower values than those reported here for the same age range were found in six infants aged from 6 weeks to 10 months. It was implied that lead may have had some bearing on the cause of the stillbirths, although it was acknowledged by the authors that other potential causes had not been excluded.

\section{SOFT TISSUES}

Horiuchi et al ${ }^{19}$ and Barltrop ${ }^{20}$ showed the influence of fetal maturity on the lead content in the liver, both the concentration and total content increasing with fetal development after the twentieth week of gestation. The mean concentrations reported by Horiuchi ${ }^{19}$ in the liver, kidney, lung, and muscle were higher than those found in the study reported here in stillbirths and neonatal infants, but lower in 
the spleen and comparable in the lung, brain, and heart.

The concentrations of lead found by Schroeder and Tipton ${ }^{11}$ in 22 fetal samples of aorta, liver, kidney, lung, brain, and heart were either lower than or similar to those found in adults. Measurement was by ash weight, which in soft tissues would give results some 50-100 times greater than by wet-weight measurement. ${ }^{6}$ Hansmann and Perry ${ }^{12}$ found concentrations of lead in the liver that were comparable in the fetus and in children, measured on dry weight of tissue. Their results, on conversion to wet weight by twofold division, gave values greatly exceeding some other investigators, including Grandjean, ${ }^{9}$ who measured the dry-weight concentrations of lead in the livers of six children, which, on conversion to wet weight, gave results similar to those reported here. Zaworski and Oyasu ${ }^{23}$ showed lower concentrations of lead in the brains of children than in those of adults, although the values in both were higher than those recorded in this report.

In a study by Casey and Robinson ${ }^{21}$ on the concentrations of several metals found in dry weight of fetal tissues, the mean values for lead in the liver and kidney were similar, on conversion to wet weight, to the values reported here in the infant group, but were greater in the brain, heart, lung, and skeletal muscle, which approximated to adult values; the analytical limit for the detection of lead in the tissues was reported as $0.1 \mathrm{ppm}$ dry weight, which might suggest a limitation in analytical capability.

\section{Conclusions}

In this study the mean concentrations of lead in the tissues of infants were found to be less than in older children, or in adults, and less in stillbirths than in neonatal live births. This suggests that prenatal and neonatal infants are less exposed to lead than at later stages in life and that the disease factors responsible for the deaths of the infants did not appear to influence, or to be influenced by, the presence of lead in their tissues. It would seem probable that there may be an element of placental function that reduces the transfer of lead from the mother to the fetus. This supposition is supported in a study by Baglan et al, ${ }^{24}$ which showed a higher concentration of lead in the placenta than in maternal or fetal blood and a higher concentration in maternal than in fetal blood.

Although the concentrations of lead in the bones of infants were lower than in older children and in adults, the patterns of distribution of lead in the bones between the age groups appeared to differ little, as shown by the ratio of ash-weight and wet- weight measurement.

No sex-related difference was observed in the tissue lead concentrations in infants, in contrast to men and women, and, over more than a decade, no change to suggest a time-related trend in lead concentrations was noted in their tissues.

Although the data do not give information on the question of sensitivity to lead they do suggest that the mechanism for the uptake of lead in most infants and older children does not differ fundamentally from that in adults. If, on a dose-related basis, young children absorbed and retained appreciably more lead than adults, then it would be reasonable to expect to have found more lead in their tissues. That this was not confirmed suggests that either (1) there is no basic physiological difference between children and adults, (2) the excretory mechanisms in children are more effective, or (3) their exposure to lead is less than that of adults. The data imply that infant exposure to lead had been less than in adults, but that in older children exposure approximated to adult levels, and also that any physiological differences, such as greater intestinal absorption but more rapid excretion as suggested by Ziegler et al, ${ }^{25}$ were probably in balance.

The results of this investigation, which for the most part gave low mean concentrations of lead in the tissues examined, relative to adults, did not suggest that the children, drawn from a heavily populated and highly industrialised area of Britain, had experienced excessive exposure to lead.

Data charts not published in this paper are available on request.

I thank Mr D Skelding and his staff at the Lostock Green laboratory of The Associated Octel Company Limited who undertook the analytical work, Mr W Unsworth and $\mathrm{Mr}$ A Hickson for the collection of samples, Mr F Murray and Mrs D E Lowe for data assembly and secretarial help, Dr D Turner for advice on presentation of the data; and Mr J Church for his statistical appraisal.

\section{References}

${ }^{1}$ Barry PSI. A comparison of concentrations of lead in human tissues. Br J Ind Med 1975;32:119-39.

2 Barry PSI, Mossman DB. Lead concentration sin human tissues. Br J Ind Med 1970;27:339-51.

${ }^{3}$ Barry PSI. A comparison of lead concentrations in human bones and in soft tissues. International Symposium on Environmental Health Aspects of Lead. Luxembourg: Commission of the European Communities, 1973: 415-26. (Euratom 5004.)

${ }^{4}$ Hislop JS, Parker A, Spicer GS, Webb MSW. The determination of lead in human rib bone. Harwell: AERE, 1973. (AERE R-7321.)

${ }^{5}$ Gross SB, Pfitzer EA, Yeager DW, Kehoe RA. Lead in 
human tissues. Toxicol Appl Pharmacol 1975;32:638-51.

${ }^{6}$ Barry PSI. Distribution and storage of lead in human tissues. In: Nriagu JO, ed. The biogeochemistry of lead in the environment. Amsterdam: Elsevier/North-Holland Biomedical Press, 1978:97-150.

${ }^{7}$ Barth E. Investigations of the lead content of human bones. Virchows Arch Pathol Anat Physiol 1931;281:146-52.

${ }^{8}$ Weyrauch F, Muller H. So-called normal lead in the human body. Zeitschrift fur Hygiene 1933;115:216-21.

${ }^{9}$ Grandjean P. Lead in Danes-historical and toxicological studies. In: Coulston FC, Korte F, eds. Environmental quality and safety. Suppl Vol II, Lead. Stuttgart: Thieme; London: Academic Press, 1975:6-75.

${ }^{10}$ Holtzman RB, Lucas HF, Ilcowicz FH. The concentration of lead in human bone. Illinois: Argonne National Laboratory, 1978:43-9. (ANL 7615.)

${ }^{11}$ Schroeder HA, Tipton IH. The human body burden of lead. Arch Environ Health 1968;17:965-78.

${ }^{12}$ Hansmann GH, Perry MC. Lead absorption and intoxication in man unassociated with occupations or industrial hazards. Arch Pathol 1940;30:226-39.

${ }^{13}$ Henderson DA, Inglis JA. The lead content of bone in chronic Bright's disease. Aust Ann Med 1957;6:145-54.

${ }^{14}$ Kehoe RA. The metabolism of lead in man in health and disease. Journal of the Royal Institute of Public Health, $1961 ; 24: 81-96,101-20,129-43$. (Harben lectures.)

${ }^{15}$ Nusbaum RE, Butt EM, Gilmour TC, Didio SL. Relation of air pollutants to trace metals in bone. Arch Environ Health 1965;10:227-32.

${ }^{16}$ Krause DP. Stable lead in human bone. Illinois: Argonne National Laboratory, $1961: 77-80$. (ANL 6398.)

${ }^{17}$ Weinig E, Borner B. Uber den normalen Bleigehalt der menschlichen Knochen. Arch Toxicol 1961 ;19:34-48.

${ }^{18}$ Tompsett SL, Anderson AB. II The lead content of human tissues and excreta. Biochem J 1935;29:1856-64.

${ }^{19}$ Horiuchi K, Horiguchi S, Suekane M. Studies on industrial lead poisoning. Osaka City Med J 1959;5:41-70.

${ }^{20}$ Barltrop D. Transfer of lead to the human foetus. Mineral metabolism in paediatrics. Oxford-Edinburgh: Blackwell, 1974:135-51.

${ }^{21}$ Casey CE, Robinson MF. Copper, manganese, zinc, nickel, cadmium, and lead in human foetal tissues. $\mathrm{Br} J$ Nutr $1978 ; 39: 639-46$.

${ }^{22}$ Bryce-Smith D, Deshpande R R, Hughes J, Waldron HA. Lead and cadmium levels in stillbirths. Lancet, 1977; i:1159.

${ }^{23}$ Zaworski RE, Oyasu R. Lead concentration in human brain tissue. Arch Environ Health 1973;27:383-6.

${ }^{24}$ Baglan RJ, Brill AB, Schulert A, et al. Utility of placental tissues as an indicator of trace element exposure to adult and fetus. Environ Res 1974;8:64-70.

${ }^{25}$ Ziegler EE, Edwards BB, Jensen RL, et al. Absorption and retention of lead by infants. Pediatr Res 1978;12:29-34. 